\title{
Mechanical behavior of Emirati red shale fillers/unsaturated polyester composite
}

\author{
Abdel-Hamid I. Mourad ${ }^{1}$ (D ) Basim Abu-Jdayil ${ }^{2} \cdot$ Muzamil Hassan $^{2}$
}

Received: 10 November 2019 / Accepted: 17 February 2020 / Published online: 27 February 2020

(c) Springer Nature Switzerland AG 2020

\begin{abstract}
Herein, we focus on the formulation of polymer-based heat insulators using natural local shale as a filler. The polymer composite was fabricated by blending unsaturated polyester resin with local natural Emirati shale of filler of different filler sizes and solidifying the obtained thermosetting blends. The prepared samples are subjected to compressive strength, flexural strength, and tensile strength tests. The obtained results indicate that these composites exhibit mechanical properties superior to those of commercial heat insulators and comparable with those of other building materials. Specially, the prepared composite features a much higher tensile strength (20-40 MPa) than conventional heat insulators $(<1 \mathrm{MPa})$.
\end{abstract}

Keywords Heat insulation $\cdot$ Composite $\cdot$ Emirati shale $\cdot$ Mechanical properties $\cdot$ Polyester $\cdot$ Water retention

\section{Introduction}

The United Arab Emirates (UAE) is the world's eighth largest oil producer with a $3.38 \%$ share of the global daily oil production. However, the easy availability of petroleum fuel makes UAE a country with one of the highest levels of per capita energy consumption in the world and leads to a constantly increasing level of carbon dioxide emission, which necessitates the development of alternatives to carbon-based fuels for power generation and cooling purposes. Moreover, the steadily increasing residential and commercial energy consumption caused by the variation of climatic conditions makes energy conservation a research area of global importance. Energy can be conserved by either exercising more stringent control over its usage or by increasing the efficiency of its utilization, with the latter option being preferred in view of the increasing global demand for energy. Therefore, heat insulators are gradually gaining importance as a means of saving energy, being utilized in building materials and certain industrial hardware.

Heat insulation materials contribute to energy conservation by reducing energy losses in various constructions and help to maximize the efficiencies of heating and cooling systems, additionally decreasing their initial installation costs. Moreover, energy conservation decreases the emission of carbon dioxide and other harmful gases [1] and facilitates the creation of comfortable ecosystems for living. Most heat insulators are composites, i.e., contain polymer materials, fillers, and other additives. Building heat insulators can be broadly classified as either inorganic (e.g., glass, rock, slag wool, and ceramics) or organic

Abdel-Hamid I. Mourad: On Leave From Mechanical Design Department, Faculty of Engineering, Helwan University, Cairo, Egypt

Electronic supplementary material The online version of this article (https://doi.org/10.1007/s42452-020-2284-4) contains supplementary material, which is available to authorized users.

Abdel-Hamid I. Mourad, ahmourad@uaeu.ac.ae| ${ }^{1}$ Department of Mechanical Engineering, College of Engineering, United Arab Emirates University, P.O. Box 15551, Al-Ain, UAE. ${ }^{2}$ Department of Chemical and Petroleum Engineering, College of Engineering, United Arab Emirates University, P.O. Box 15551, Al Ain, UAE. 
(e.g., cellulose, cotton, wood, pulp, cane, synthetic fibers, cork, foamed rubber, melamine foam, polystyrene, polyethylene, polyurethane, and other polymers) materials. Although the physicochemical stability of polymers generally makes them good heat insulators, their mechanical properties can be further improved or modified by the addition of inorganic fillers to afford composites with enhanced strength [2-9]. Moreover, heterogeneity the composite should be tested to confirm the isotropic behavior $[10,11]$.

Clay minerals such as bentonite, kaolin, talc, and mica are often used as inorganic fillers in conventional polymer composites to reduce their cost and/or to impart special properties such as high modulus, hardness, thermal stability, electrical insulation, thickening, opacity, and brightness [12-16]. Heat insulation materials available on the local market are relatively expensive and are mostly used by local contractors and small-size entrepreneurs. In addition, typical insulation materials such as polyurethane, polystyrene, and mineral wool [17] exhibit poor mechanical properties, thus being of only limited use for the construction process. Consequently, one needs to develop new insulating materials with improved mechanophysical performance that allow energy saving/water leakage prevention and additionally exhibit the advantages of ease of handling and machining $[13,15]$ while being relatively cheap and suitable for general-purpose use by regular consumers. Much effort has recently been directed at the development of composite heat insulation materials, e.g., polyester filled with scrap tires [18] or date wood/pits [19] showing acceptable tensile and compressive strengths compared to commercially available materials, although the mechanical properties of these composites markedly deteriorate with increasing filler content. Chikhi et al. [20] investigated the effect of date palm fiber on the thermal conductivity and water absorption/mechanical properties of gypsum-based materials, concluding that these novel biocomposites exhibit good thermal and mechanical performance and can therefore be applied as heat insulation materials. Benmansour et al. [21] showed that date palm wood is a good candidate for the development of efficient and safe insulating materials compared to other natural materials. Al-Malah and Abu-Jdayil [10] formulated a polymeric heat insulator using different types of local Jordanian filler, demonstrating that a bentonite-based unsaturated polyester (UPE) composite exhibits stable and compatible thermal, physical, and chemical properties and is a promising heat insulator for both domestic and industrial applications.

Generally, clays and rocks can enhance the mechanical properties of thermosetting resins. Ruban et al. [22] studied the chemical resistance and mechanical properties of UPE/organoclay nanocomposites, showing that their tensile and flexural characteristics were strongly dependent on clay content and further demonstrating that these composites can be used as heat insulators with excellent resistance to non-aqueous solvents. Qian et al. [23] investigated the effect of vermiculate (mineral found in typical rocks and limestone) reinforcement in polyurethane. The composites showed $a>270 \%$ increase in tensile modulus and $>60 \%$ increase in tensile strength compared to pure polyurethane. The composite was prepared using three different compositions of limestone $(5 \%, 7.5 \%$, and $10 \%)$. The result shows that with the addition of limestone, flexural strength increased from $159 \mathrm{MPa}(5 \%)$ to $165 \mathrm{MPa}$ (10\%). Meanwhile, tensile strength reduced from 17 (5\%) to $14 \mathrm{MPa}(10 \%)$.

Herein, we focus on the formulation of polymer-based heat insulators using natural local shale as a filler. Specifically, liquid unsaturated polyester was blended with the filler at different polymer/filler ratios and solidified during thermosetting. Physical and thermal properties of Emirati red shale/ polyester composites were reported in our previous studies [24]. The promising results (summarized in Table 1) motivated the research group to investigate the mechanical integrity and performance of the developed composites. Thus, in the current work, the fabricated solid samples were subjected to different mechanical tests to come up with a product formulation having optimal properties.
Table 1 Thermal and physical properties of polyester, polyester/shale composite

\begin{tabular}{llll}
\hline Properties & Pure polyester & $\begin{array}{l}\text { UPE/shale com- } \\
\text { posite (10\%) }\end{array}$ & $\begin{array}{l}\text { Polyester/ } \\
\text { shale } \\
\text { composite } \\
(50 \%)\end{array}$ \\
\hline Thermal conductivity $k(\mathrm{~W} / \mathrm{mK})$ & & 0.15 & 0.22 \\
Bulk density $\rho\left(\mathrm{g} \mathrm{cm}^{-3}\right)$ & 0.15 & 1.2 & 1.55 \\
Water retention at $50^{\circ} \mathrm{C}(\mathrm{wt} \%)$ & 1.17 & 0.25 & 0.89 \\
Resistance to chemicals-citric acid (wt\%) & 0.22 & 0.1 & 0.18 \\
Microstructure (scanning electron microscopy) & No microgaps & No microgaps & $\begin{array}{l}\text { Microgaps } \\
\text { were } \\
\end{array}$ \\
& & & observed \\
\hline
\end{tabular}




\section{Materials and methods}

\subsection{Rock shale}

Rock shale obtained from the Emirates Ceramic Factory (subsidiary of Fujairah Building Industries P.S.C., Fujairah) was mainly extracted from rocky sand in the districts of Fujairah and Ras Al Khaimah in the UAE, containing silica (17.16 wt\%) and alumina (64.18 wt\%) as major constituents along with traces of other metal and nonmetal oxides.

The obtained rock shale was powdered to three different grain sizes, namely size $1(<100 \mu \mathrm{m})$, size 2 $(100-200 \mu \mathrm{m})$, and size $3(200-300 \mu \mathrm{m})$.

\subsection{Unsaturated polyester (UPE)}

The polyester resin (Polylite $721-800 \mathrm{E}, 44-46 \%$ styrene, viscosity $=280-330 \mathrm{mPa}$ s) and methyl ethyl ketone peroxide were obtained from Reichhold Norpol Company (Dubai). The advantages of UPE include its ease of handling, low water absorption, low cost, good mechanical properties, transparency, and rapid room-temperature curing without gas evolution [3]. The individual polymer chains of UPE are cross-linked during curing, allowing it to be mold-cast and laminated at lower temperature and pressure than other thermosetting resins [25].

\subsection{Fabrication of molds and composites}

\subsubsection{Molds}

Three series of stainless-steel molds were fabricated according to ASTM standard recommendations for molding to produce standard specimens for mechanical tests.

\subsubsection{Composites}

Composites with different filler contents ( $0-60$ vol\%) and high mixing degrees were prepared at room temperature. A specified amount of shale was gradually added to polyester resin under continuous mixing, and methyl ethyl ketone peroxide was subsequently added to initiate thermosetting. The composite was fabricated at every $10 \%$ interval. The obtained mixture was poured into the suitable stainless-steel mold, the interior surface of which was coated with paraffin wax to prevent sticking $[24,26,27]$.

\subsection{Microstructure}

Scanning electron microscopy-FEI Quanta 200 ESEM was used to investigate the microstructure of samples. Samples were finely powdered and gold sputtered to make them conductors, and the images were taken at a different resolutions.

\subsection{Mechanical tests}

Composite samples were subjected to tension, compression, and bending tests in accordance with ASTM standards. All mechanical tests were performed using a universal testing machine (MTS Model 20/mh, capacity $=100 \mathrm{kN}$ ). Tension tests were performed by stretching the tensile specimens of overall length $=100 \mathrm{~mm}$, gage length $=30 \mathrm{~mm}$, width $=10 \mathrm{~mm}$, and thickness $=5 \mathrm{~mm}$ at an overhead speed of $2 \mathrm{~mm} / \mathrm{min}$ until full separation. The tensile tests were conducted according to ASTM C 190-85. The flexural (three-point bending) tests were carried out, using the abovementioned universal testing machine, on rectangular specimens with a cross-sectional area of $4 \times 12.5 \mathrm{~mm}^{2}$ and a length of $65 \mathrm{~mm}$ according to ASTM D790-00. Compression tests were performed on cylindrical specimens of length $=30 \mathrm{~mm}$, diameter $=25 \mathrm{~mm}$ according to ASTM D695-15. In all tests, the results were reported as averages of 3-5 measurements.

\section{Results and discussion}

\subsection{Morphology of composites}

Scanning electron microscope (SEM) images were analyzed to visualize the distribution of the fillers in the UPE matrix. We have analyzed the effect of size 1 (as a representative) filler loading on the morphology of the composite. Figure 1 shows the SEM images of cross sections of pure polyester and UPE-shale (size 1) composite specimen with $10 \%$ and $50 \%$ reinforcement. The composite specimens shows that the shale particles are properly mixed in the UPE matrix. However, microgaps were observed in $50 \%$ filler-loaded composite specimens (Fig. 1c, d), and this may be due to weak interfacial adhesions between filler and polyester matrix. However, no microgaps were observed in composites with $10 \%$ filler content. This is because of high volume fraction of polyester comparing to the filler. These microgaps may affect the mechanical properties of the composites at high filler loading.

\subsection{Tensile testing}

For tensile strength analysis, samples clamped between the two jaws of the MTS machine were strained at a constant rate of $2 \mathrm{~mm} / \mathrm{min}$ until sample failure. Figure 2 shows tensile stress-strain curves for representative samples filled with size- 1 , size- 2 , and size- 3 shale. The stress increases linearly with strain at the beginning with some 

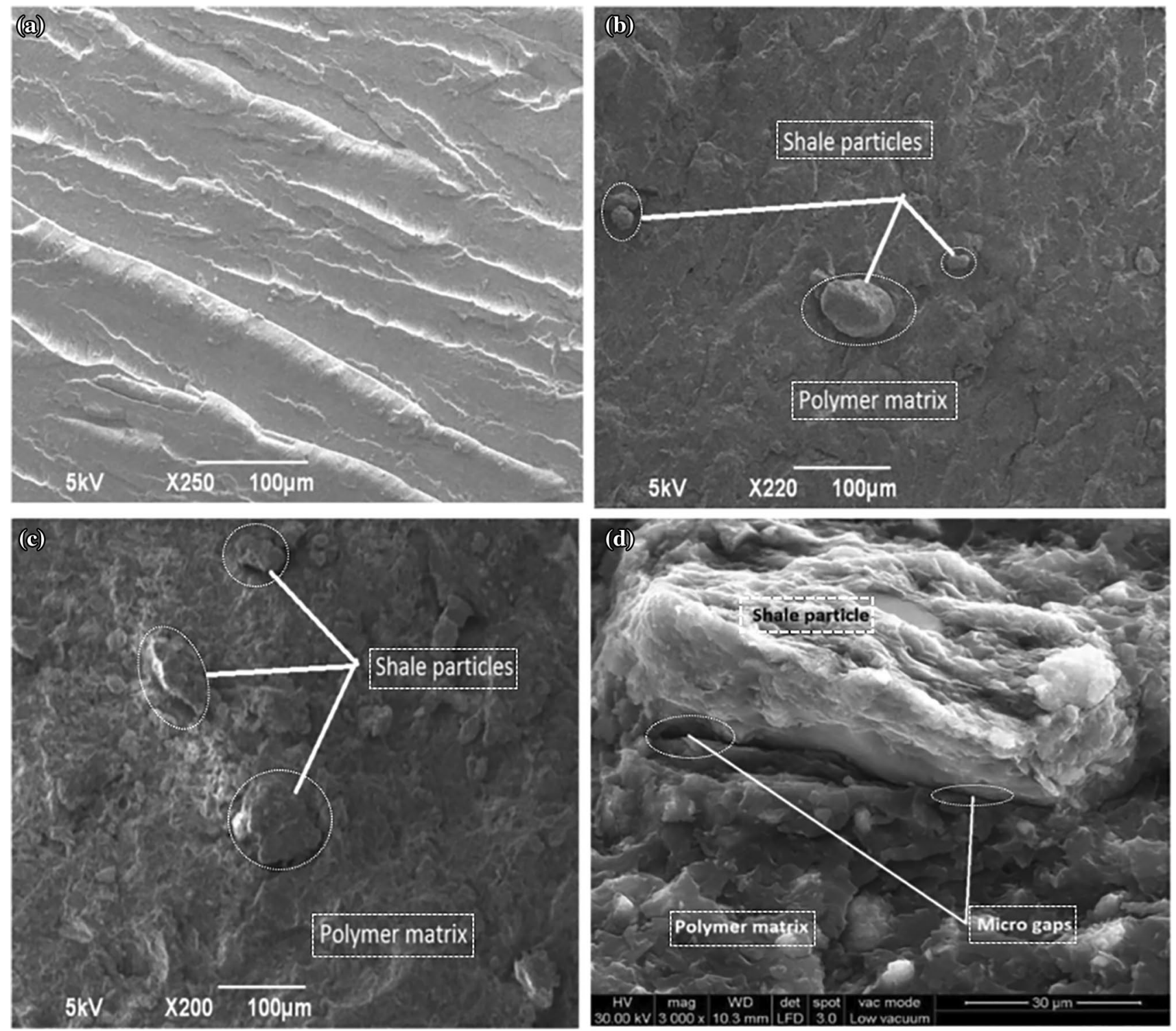

Fig. 1 SEM images of pure polyester (a), UPE-shale composite specimen with $10 \%$ (b) and $50 \%$ (c) d) filler loading

nonlinearity before fracture [28-30]. Such nonlinearity disappeared with increasing the filler content. Pure polyester samples exhibited higher tensile strength and elongation at break than composite ones, which, exhibited elevated stiffness that increased with filler content.

The tensile strength of UPE composites decreased after reinforcement with shale filler, i.e., neat UPE specimens exhibited a maximum stress of $41.4 \mathrm{MPa}$, whereas shale-reinforced ones exhibited smaller values of ultimate strength $\left(\sigma_{\mathrm{u}}\right)$, as shown in Table 2 .

The observation of higher tensile strength at lower filler content was attributed to the better dispersion of shale in the polyester resin matrix, the absence of voids or pores, and good interfacial bonding at low filler loading.
On the other hand, the low tensile strength at high filler content was attributed to inefficient stress transfer at the particle-matrix interface due to poor interfacial adhesion, particle-to-particle contact, and the presence of voids or pores. Similar observations were reported, in our recent publication [18], on similar behavior of polyester/scrap tire composites. Patnaik et al. has observed that the mechanical properties are getting reduced when fillers, such as fly ash, alumina, and silica are added to polyester/glass composite [31]. Mourad et al. [9] have observed a degradation in the mechanical performance of kevlar/epoxy composite due to agglomeration when more than $0.5 \%$ of MWCNT were added to polymer (epoxy) matrix. Similar 

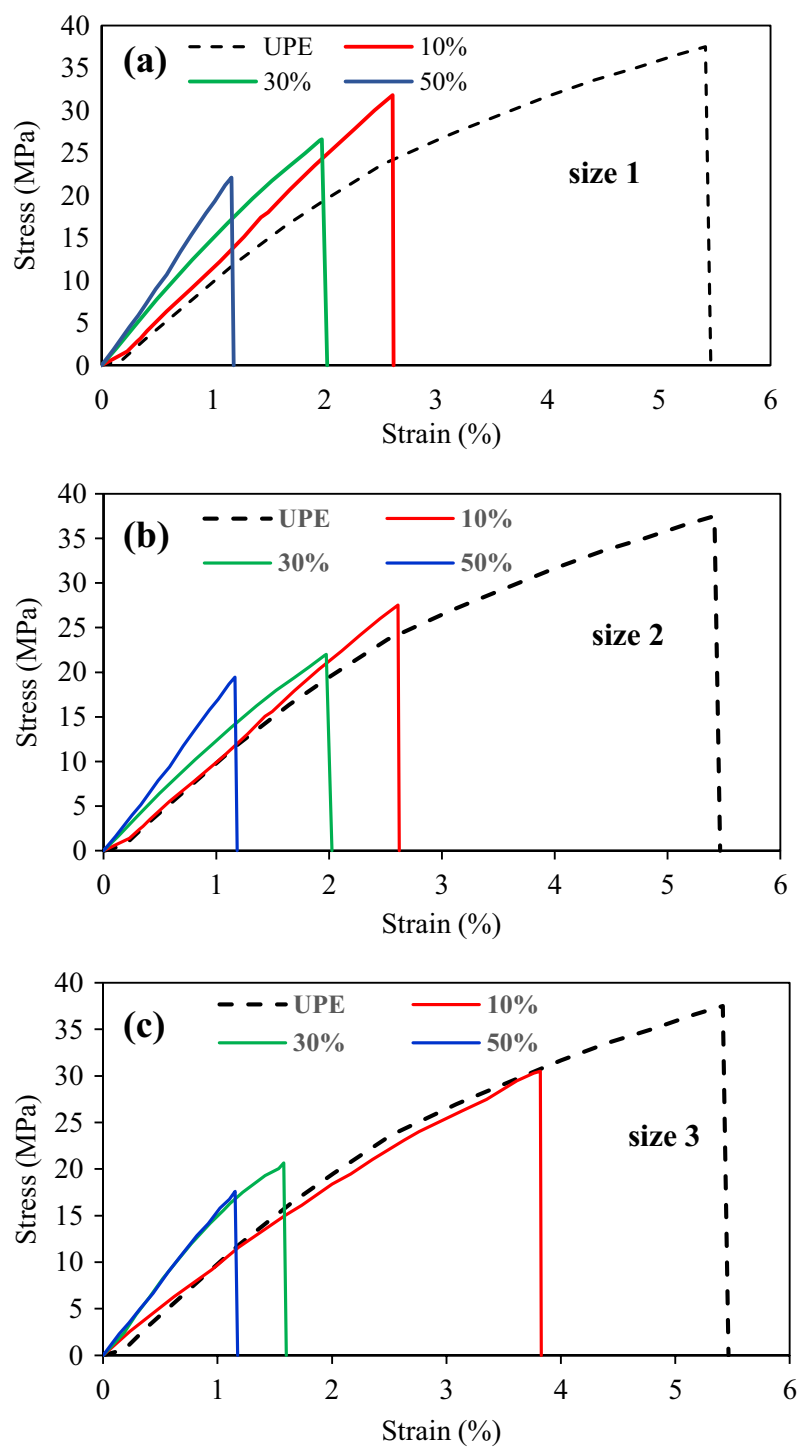

Fig. 2 Tensile stress-strain curves for a size-1, b size-2, and c size 3 samples with various shale volume fractions

observations were reported in $\mathrm{HDPE} / \mathrm{ZnO}$ composites [4] and $\mathrm{SiC}$-reinforced aluminum matrix composites [7].

Figure 3 illustrates the variation of tensile strength with filler volume fraction for three filler sizes, demonstrating that at a given filler content, composites containing smaller particles featured higher tensile strength, which was ascribed to the better dispersion and filler-matrix interactions therein. Similar observations have been reported by Bigg [32] and Fuad et al. [33] for other filled systems (commercial fumed silica and talc). However, Fan et al. [34] observed a decrease in the tensile strength of polypropylene composites with increasing clay content

The results of tensile strength testing demonstrated that size- 1 shale composites exhibited higher tensile strength than size-2 and size-3 ones. However, all prepared composites showed tensile strengths superior to those of commonly used insulating materials such as foam glass $(0.150 \mathrm{MPa})$, mineral fiber $(0.015 \mathrm{MPa})$, and polystyrene (0.186 MPa) [35-37].

\subsection{Compression testing}

Compressive strength is the capacity of a material to withstand axially directed pushing forces. Here the specimens were held between the two platforms of the testing machine, and a load was applied over a $25-\mathrm{mm}$ span length at a constant overhead speed of $10 \mathrm{~mm} / \mathrm{min}$. Pure polyester samples flatten without failure, whereas composite samples fractured before the $25 \mathrm{~mm}$ could be achieved.

Figure 4 shows compression stress-strain curves recorded for composite samples of the three different shale particle sizes. The curve of pure UPE is included for comparison. The curves of all cases show similar trends. A linear stress-strain relationship is observed at the first stage of loading prior the 1st peak takes place then the stress reduces with the strain prior increasing again till failure occurs. The modulus of elasticity is determined from the first stage of the curve while the yield and ultimate strengths are measured at the first peak and highest achieved stress before failure. This performance has been observed by Mourad et al. [38-41].

The obtained mechanical properties (yield strength $\sigma_{y}$, ultimate stress $\sigma_{u}$, and modulus of elasticity $E$ ) are presented in Table 3. Figure 5 illustrates the variation of compressive strength with filler content for three filler particle sizes. Generally, the compressive strength of UPE matrices is the highest and tends to decrease with increasing filler size and content. With the addition of $60 \%$ shale, comparing to UPE the compressive strength of size 1 , size 2 , and size 3 composites reduced by $12 \%, 21 \%$, and $36 \%$ respectively. This could be because of the concomitant formation of voids. Thus, the decrease in compressive strength observed for increasing shale content was ascribed to the concomitant increase in matrix porosity due to air entrainment and poorer shale/matrix adhesion. This is supported by the SEM analyses in our previous work [24]. However, all prepared composites showed compressive strengths superior to those of other composites commonly used as lightweight construction materials (e.g., composites of cement, sand, and coconut and durian fiber (2.4-3.3 MPa) [42], and outperforming stone masonry (estimated compressive strength $=20-30 \mathrm{MPa}$ ) [43].

Figure 6 shows comparison of the properties of all insulating materials based on filled polyester produced in our research laboratory $[18,19]$. Notably, the saturation content of rock shale, date wood, and date pit fillers equaled $60 \mathrm{vol} \%$, whereas for rubber it was limited to 
Table 2 Tensile strengths of samples with different filler contents

\begin{tabular}{|c|c|c|c|c|c|c|}
\hline \multirow{2}{*}{$\begin{array}{l}\text { Filler con- } \\
\text { tent (vol\%) }\end{array}$} & \multicolumn{2}{|l|}{ Size 1} & \multicolumn{2}{|l|}{ Size 2} & \multicolumn{2}{|l|}{ Size 3} \\
\hline & $\begin{array}{l}\text { Ultimate } \\
\text { strength (MPa) }\end{array}$ & $\begin{array}{l}\text { Standard } \\
\text { deviation }\end{array}$ & $\begin{array}{l}\text { Ultimate } \\
\text { strength (MPa) }\end{array}$ & $\begin{array}{l}\text { Standard } \\
\text { deviation }\end{array}$ & $\begin{array}{l}\text { Ultimate } \\
\text { strength (MPa) }\end{array}$ & $\begin{array}{l}\text { Standard } \\
\text { deviation }\end{array}$ \\
\hline 0 & 41.38 & 3.56 & 41.38 & 3.56 & 41.38 & 3.56 \\
\hline 5 & 40.52 & 1.98 & - & - & - & - \\
\hline 10 & 31.80 & 3.25 & 31.53 & 4.88 & 30.8 & 0.42 \\
\hline 15 & 31.57 & 3.98 & - & - & - & - \\
\hline 20 & 29.20 & 3.12 & 28.55 & 3.25 & 25.97 & 2.25 \\
\hline 25 & 25.63 & 5.19 & - & - & - & - \\
\hline 30 & 26.60 & 4.24 & 25.87 & 3.82 & 19.37 & 1.12 \\
\hline 35 & 26.57 & 1.26 & - & - & - & - \\
\hline 40 & 26.62 & 1.63 & 18.37 & 0.59 & 17.07 & 1.56 \\
\hline 45 & 22.35 & 2.47 & - & - & - & - \\
\hline 50 & 22.12 & 3.03 & 17.77 & 3.06 & 15.90 & 2.54 \\
\hline 55 & 21.19 & 2.63 & - & - & - & - \\
\hline 60 & 18.87 & 2.15 & 15.68 & 4.01 & 12.13 & 0.23 \\
\hline
\end{tabular}

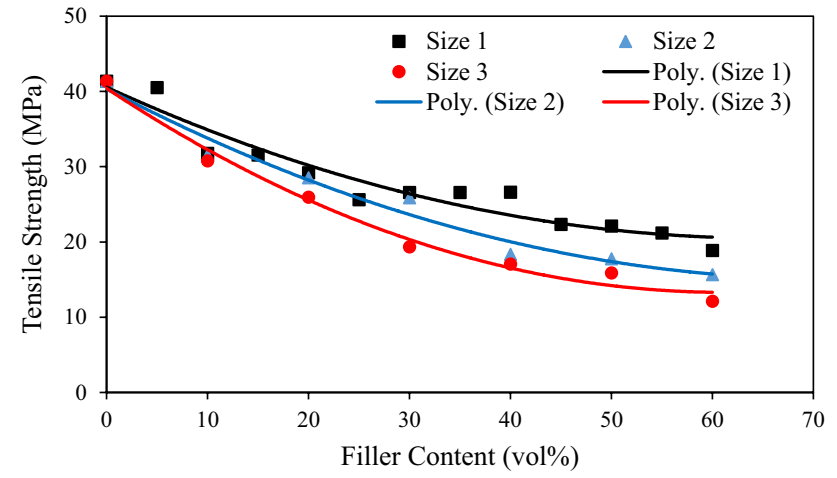

Fig. 3 Effect of filler content and size on the tensile strength of composites

$40 \mathrm{vol} \%$. Interestingly, the addition of 10 vol\% rock shale and date wood did not affect the compression strength of the composite. This can be related to the microstructure of the composite [24]. It has been observed in the previous studies that, up to $10 \%$ shale incorporation, there is much better interfacial adhesion between shale and polyester. When percentage of filler content increases, there are microvoids seen in the composite specimen which affected the compression properties of the shale/polyester composite. Moreover, an overall performance comparison indicated that at higher filler concentrations, best mechanical stability was obtained for size 1 rock shale.

\subsection{Flexural testing}

Figure 7 presents the load-deflection curves obtained for different filler contents and filler particle sizes, and the flexural test results are summarized and Table 4 . The load

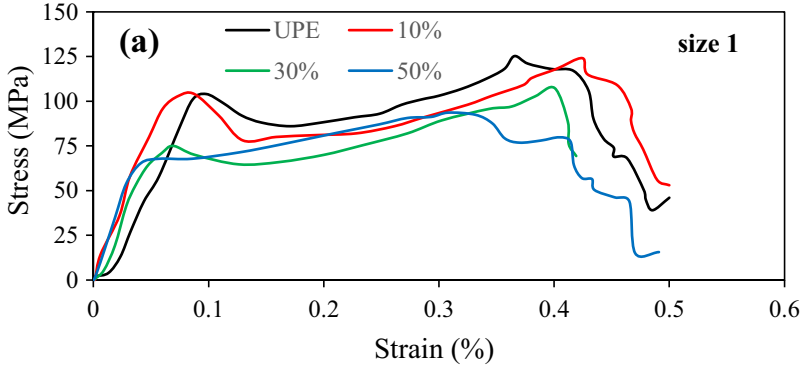

Size-1 stress - strain curves for various shale volume fractions

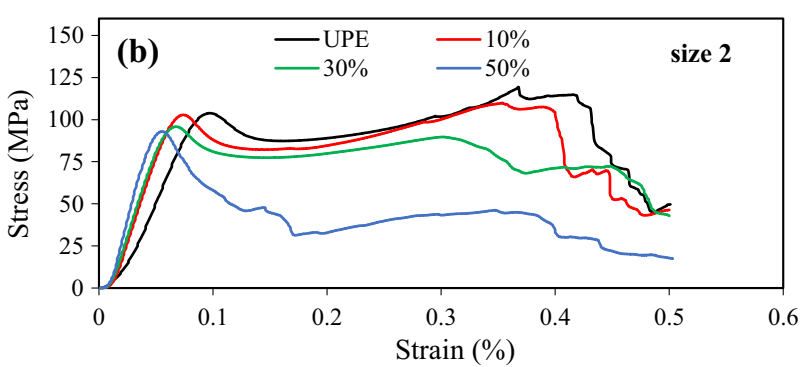

Size-2 stress - strain curves for various shale volume fractions.

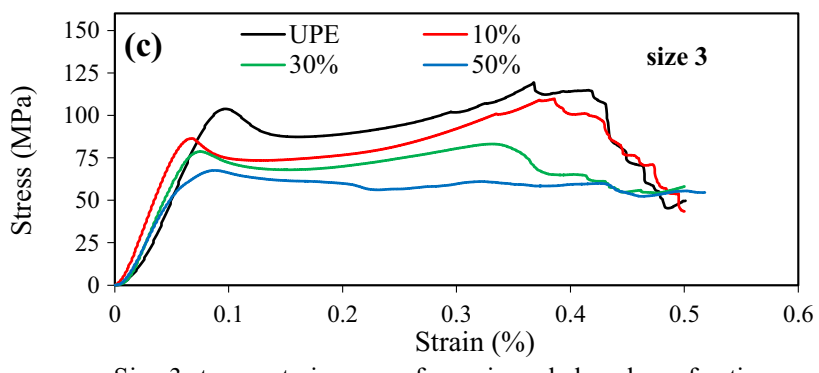

Size-3 stress - strain curves for various shale volume fractions.

Fig. 4 Compression stress-strain curves for a size-1, b size-2, and c size 3 samples with various shale volume fractions 
Table 3 Compression test results of all samples

\begin{tabular}{|c|c|c|c|c|c|c|c|c|c|}
\hline \multirow{2}{*}{$\begin{array}{l}\text { Filler } \\
\text { content } \\
\text { (vol\%) }\end{array}$} & \multicolumn{3}{|l|}{ Size 1} & \multicolumn{3}{|l|}{ Size 2} & \multicolumn{3}{|l|}{ Size 3} \\
\hline & $\sigma_{y}(\mathrm{MPa})$ & $\sigma_{\mathrm{u}}(\mathrm{MPa})$ & $E(\mathrm{MPa})$ & $\sigma_{y}(\mathrm{MPa})$ & $\sigma_{\mathrm{u}}(\mathrm{MPa})$ & $E(\mathrm{MPa})$ & $\sigma_{\mathrm{y}}(\mathrm{MPa})$ & $\sigma_{\mathrm{u}}(\mathrm{MPa})$ & $E(\mathrm{MPa})$ \\
\hline 0 & 107.27 & 125.21 & 1220.9 & 107.27 & 125.21 & 1220.9 & 107.27 & 125.21 & 1220.9 \\
\hline 5 & 106.54 & 124.43 & 1364.47 & & & & & & \\
\hline 10 & 104.22 & 124.07 & 1311.57 & 104.86 & 109.43 & 1452.27 & 93.66 & 115.33 & 1270.15 \\
\hline 15 & 103.52 & 119.17 & 1707.50 & & & & & & \\
\hline 20 & 101.06 & 112.57 & 1600.7 & 100.01 & 102.27 & 1666.89 & 89.56 & 99.47 & 1189.34 \\
\hline 25 & 100.74 & 109.93 & 1686.24 & & & & & & \\
\hline 30 & 100.08 & 107.33 & 1338.26 & 93.74 & 93.73 & 1625.71 & 84.36 & 86.54 & 1223.33 \\
\hline 35 & 98.12 & 103.27 & 1629.34 & & & & & & \\
\hline 40 & 97.15 & 100.87 & 1678.9 & 92.69 & 92.67 & 1591.43 & 78.21 & 78.22 & 1197.63 \\
\hline 45 & 95.38 & 96.37 & 1511.22 & & & & & & \\
\hline 50 & 95.22 & 93.66 & 1593.51 & 88.65 & 88.67 & 1734.41 & 75.87 & 75.87 & 1033.65 \\
\hline 55 & 93.02 & 93.03 & 1280.18 & & & & & & \\
\hline 60 & 94.18 & 94.1 & 1305.29 & 84.31 & 84.3 & 1412.2 & 68.5 & 68.51 & 1403.3 \\
\hline
\end{tabular}

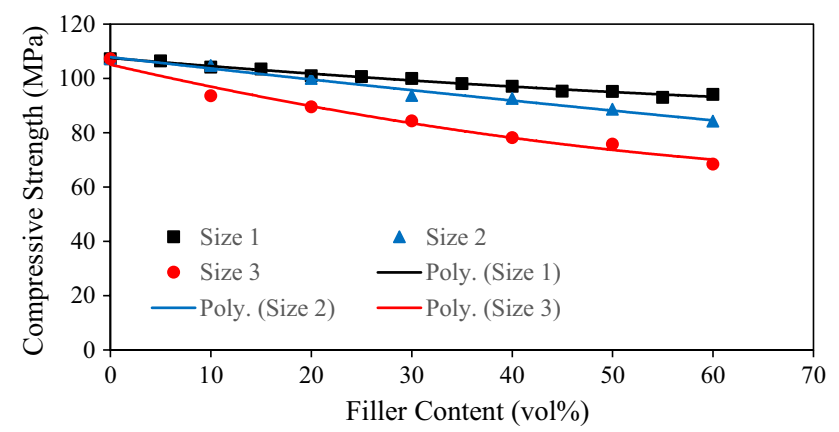

Fig. 5 Effect of filler content and size on the compressive strength of composites

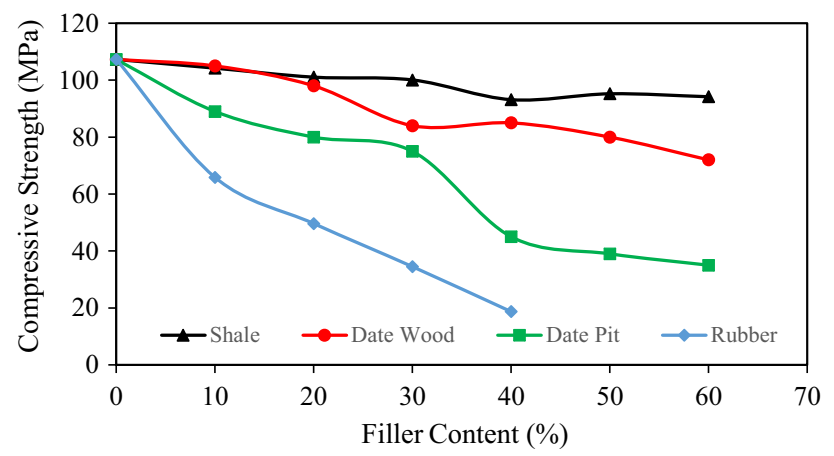

Fig. 6 Compressive strength of polyester filled with different materials

varies with the deflection in a linear relationship, at the first stage of loading, with some nonlinearity prior fracture. Such nonlinear performance disappears with filler contents. Both fracture load and deflection decrease with filler content for all filler particle sizes, which demonstrate
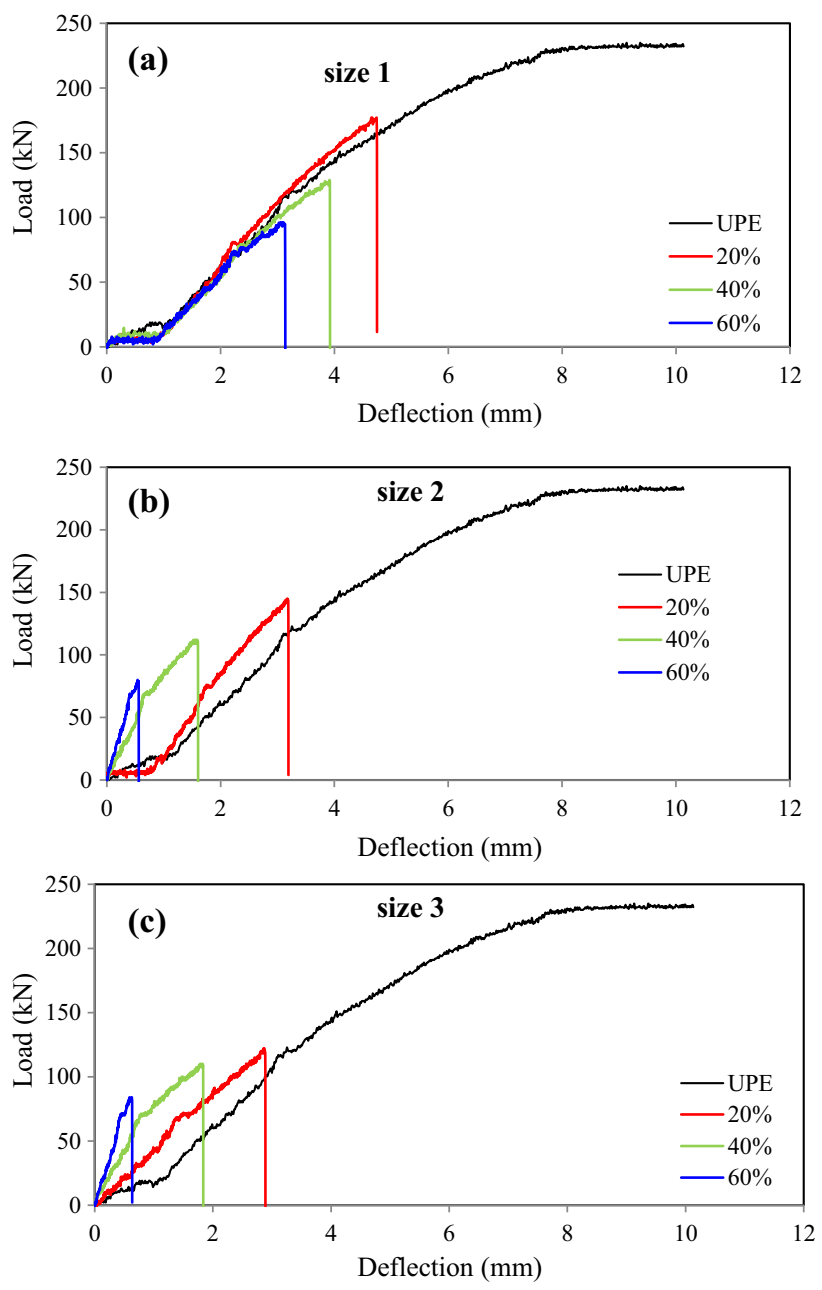

Fig. 7 Flexural load-deflection curves for developed composites samples at various shale volume fractions. a size 1 , b size 2 , and $\mathbf{c}$ size 3 
Table 4 Flexural test results

\begin{tabular}{|c|c|c|c|c|c|c|}
\hline \multirow{2}{*}{$\begin{array}{l}\text { Filler } \\
\text { content } \\
\text { (vol\%) }\end{array}$} & \multicolumn{2}{|l|}{ Size 1} & \multicolumn{2}{|l|}{ Size 2} & \multicolumn{2}{|l|}{ Size 3} \\
\hline & Peak load (kN) & $\begin{array}{l}\text { Flexural } \\
\text { strength } \\
(\mathrm{MPa})\end{array}$ & Peak load (kN) & $\begin{array}{l}\text { Flexural } \\
\text { strength } \\
(\mathrm{MPa})\end{array}$ & Peak load (kN) & $\begin{array}{l}\text { Flexural } \\
\text { strength } \\
(\mathrm{MPa})\end{array}$ \\
\hline 0 & 224.73 & 109.5 & 224.73 & 109.5 & 224.73 & 109.5 \\
\hline 20 & 182.04 & 88.74 & 161.66 & 78.8 & 115.4 & 56.25 \\
\hline 40 & 120.04 & 58.51 & 103.17 & 50.29 & 112.33 & 54.76 \\
\hline 60 & 95.24 & 46.24 & 89.67 & 43.71 & 80.6 & 39.29 \\
\hline
\end{tabular}

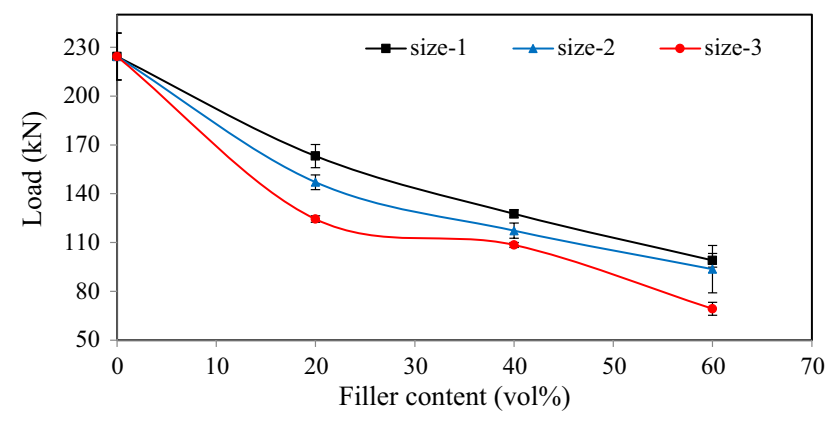

Fig. 8 Effects of filler content and size on the flexural strength of composites

that the composite flexural strength and strain decrease with filler content.

Figure 8 demonstrates the variation of fracture load with filler content for different particle sizes, revealing that the load-bearing capacity of UPE matrix decreases with increasing filler content and particle size. This can be due to the presence of microvoids and weak interfacial adhesion seen at higher shale concentrations. The observation is also in agreement with the results of the compressive strength test of Ohama et al. [44]. Moreover, particle agglomeration will create stress concentration points resulting in premature failure of the composite. Similar observations are reported by Mourad et al. [9] in kevlar/epoxy composites incorporated with MWCNT. Similarly, composites made from polyester and fillers such as date pits, date wood and rubber are found to reduce the flexural strength $[18,19]$.

\section{Conclusions}

Herein, we prepared and conducted mechanical testes to characterize a range of Emirati rock shale-filled polymer composites. In our previous work, the thermal characterization of this material as heat insulating material has been conducted, and the findings of the study revealed that it is a competitive insulating material. The results of this work showed that, the highest strength was observed for the smallest filler particle size. Moreover, the mechanical properties of these composites deteriorated with increasing filler content, i.e., an increase of filler content from 0 to $60 \mathrm{vol} \%$ decreased the tensile strength, compression strength, and flexural load-bearing capacity from 43 to $16 \mathrm{MPa}, 105$ to $68.5 \mathrm{MPa}$, and 180 to $82 \mathrm{kN}$, respectively. Nevertheless, compared to the commonly used insulating materials (such as, glass, mineral fiber and polystyrene) all polyester-shale composites described herein exhibited superior mechanical properties, thus being suitable for industrial application as a heat insulator.

\section{Compliance with ethical standards}

Conflict of interest On behalf of all authors, the corresponding author states that there is no conflict of interest.

\section{References}

1. Kazim AM (2007) Assessments of primary energy consumption and its environmental consequences in the United Arab Emirates. Renew Sustain Energy Rev 11:426-446

2. Abu-Jdayil B, Mourad A-HI, Hittini W, Hassan M, Hameedi S (2019) Traditional, state-of-the-art and renewable thermal building insulation materials: an overview. Construct Build Mater 214:709-35

3. Liu Q, Zhang Y, Xu H (2008) Properties of vulcanized rubber nanocomposites filled with nanokaolin and precipitated silica. Appl Clay Sci 42:232-237

4. Benabid FZ, Kharchi N, Zouai F, Mourad A-HI, Benachour D (2019) Impact of co-mixing technique and surface modification of $\mathrm{ZnO}$ nanoparticles using stearic acid on their dispersion into HDPE to produce HDPE/ZnO nanocomposites. Polym Polym Compos. https://doi.org/10.1177/0967391119847353

5. Krishnan PK, Christy JV, Arunachalam R, Mourad A-HI, Muraliraja R, Al-Maharbi M, Murali V, Chandra MM (2019) Production of aluminum alloy-based metal matrix composites using scrap aluminum alloy and waste materials: Influence on microstructure and mechanical properties. J Alloys Compd 784:1047-1061

6. Mourad A-HI, Zaaroura N, Cherupurakal N (2019) Wet lay-up technique for manufacturing of advanced laminated composites. Karbala Int J Mod Sci 5(1):5 
7. Idrisi AH, Mourad A-HI (2017) Fabrication and wear analysis of aluminium matrix compositereinforced by $\mathrm{SiC}$ micro and nano particles. In: ASME 2017 pressure vessels and piping conference 2017 July 16. American Society of Mechanical Engineers Digital Collection

8. Mourad A-HI, Mozumder M, Mairpady A, Pervez $\mathrm{H}$, Kannuri $U$ (2017) On the injection molding processing parameters of HDPE-TiO ${ }_{2}$ nanocomposites. Materials. 10(1):85

9. Mourad A-HI, Ayad OG, Rahman A, Hilal-Alnaqbi A, Abu-Jdayil $\mathrm{BI}$ (2016) Experimental investigation of Kevlar KM2Plus nanoreinforced laminated composite thermo-mechanical properties. In: ASME 2016 pressure vessels and piping conference 2016 July 17. American Society of Mechanical Engineers Digital Collection

10. Babaghayou MI, Mourad A-HI, Lorenzo V, Orden MU, Urreaga JM, Chabira SF, Sebaa M (2016) Photodegradation characterization and heterogeneity evaluation of the exposed and unexposed faces of stabilized and unstabilized LDPE films. Mater Des 111:279-290

11. Babaghayou MI, Mourad A-HI, Lorenzo V, Chabira SF, Sebaa M (2018) Anisotropy evolution of low density polyethylene greenhouse covering films during their service life. Polym Test 66:146-154

12. Abu-Jdayil B, Al-Malah $\mathrm{K}$ (2008) Jordanian clay-based heat insulator composites: Mechanical properties. J Reinf Plast Compos 27:1559-1568

13. Ismail MR, Ali MAM, El-Milligy AA et al (1999) Studies on sand/ clay unsaturated polyester composite materials. J Appl Polym Sci 72:1031-1038

14. Abu-Jdayil B, Al-Malah K, Sawalha R (2002) Study on bentoniteunsaturated polyester composite materials. J Reinf Plast Compos 21:1597-1607

15. Lee JY, Lee HK (2004) Characterization of organobentonite used for polymer nanocomposites. Mater Chem Phys 85:410-415

16. Al-Malah K, Abu-Jdayil B (2007) Clay-based heat insulator composites: Thermal and water retention properties. Appl Clay Sci 37:90-96

17. Cabeza LF, Castell A, Medrano M et al (2010) Experimental study on the performance of insulation materials in Mediterranean construction. Energy Build 42:630-636

18. Abu-Jdayil B, Mourad A-HI, Hussain A (2016) Investigation on the mechanical behavior of polyester-scrap tire composites. Constr Build Mater 127:896-903

19. Hittini W, Abu-Jdayil B (2019) Development of date pit-polystyrene thermoplastic heat insulator material: mechanical properties. J Thermoplast Compos Mater. https://doi. org/10.1177/0892705719847242

20. Chikhi M, Agoudjil B, Boudenne A et al (2013) Experimental investigation of new biocomposite with low cost for thermal insulation. Energy Build 66:267-273

21. Benmansour N, Agoudjil B, Gherabli A et al (2014) Thermal and mechanical performance of natural mortar reinforced with date palm fibers for use as insulating materials in building. Energy Build 81:98-104

22. Ruban YJV, Mon SG, Roy DV (2014) Chemical resistance/thermal and mechanical properties of unsaturated polyester-based nanocomposites. Appl Nanosci 4:233-240

23. Qian $\mathrm{Y}$, Lindsay $\mathrm{Cl}$, Macosko $\mathrm{C}$ et al (2011) Synthesis and properties of vermiculite-reinforced polyurethane nanocomposites. ACS Appl Mater Interfaces 3:3709-3717

24. Abu-Jdayil B, Mourad A-HI, Hassan M (2018) Development of polymeric heat insulators based on Emirati red shale filler: thermal and physical properties. Polym Compos 39:E1463

25. Aziz SH, Ansell MP, Clarke SJ et al (2005) Modified polyester resins for natural fibre composites. Compos Sci Technol 65:525-535
26. Calori GM, Mazza E, Colombo M et al (2011) The use of bonegraft substitutes in large bone defects: any specific needs? Injury 42:S56-S63

27. Mourad A-HI, Ayad OG, Rahman A et al (2016) Experimental investigation of Kevlar KM2Plus nano-reinforced laminated composite thermo-mechanical properties. In: ASME 2016 pressure vessels and piping conference. American Society of Mechanical Engineers, 2016, pp V06AT06A030-V06AT06A030.

28. Maiti SK, Namdeo S (2008) Mourad A-HI A scheme for finite element analysis of mode I and mixed mode stable crack growth and a case study with AISI 4340 steel. Nuclear Eng Des 238(4):787-800

29. Mourad A-HI, El-Domiaty A, Chao YJ (2013) Fracture toughness prediction of low alloy steel as a function of specimen notch root radius and size constraints. Eng Fract Mech 103:79-93

30. Maiti SK, Mourad A-HI (1995) Criterion for mixed mode stable crack growth-I. Three point bend geometry. Eng Fract Mech 52:321-347

31. Patnaik A, Satapathy A, Mahapatra SS et al (2009) A comparative study on different ceramic fillers affecting mechanical properties of glass-polyester composites. J Reinf Plast Compos 28:1305-1318

32. Bigg DM (1987) Mechanical properties of particulate filled polymers. Polym Compos 8:115-122

33. Fuad MYA, Ismail Z, Ishak ZAM et al (1995) Application of rice husk ash as fillers in polypropylene: effect of titanate, zirconate and silane coupling agents. Eur Polym J 31:885-893

34. Fan Y, Lou J, Shinozaki DM (2007) Microstructure dependent properties of polypropylene-clay nanocomposites. J Appl Polym Sci 103:204-210

35. Li DH, Hu ML, Wang HB et al (2011) Low temperature mechanical property of AZ91D magnesium alloy fabricated by solid recycling process from recycled scraps. Trans Nonferrous Met Soc China (English Ed) 21:1234-1240

36. Tjong SC, Liang G (2007) Electrical behavior of high density polyethylene/ZnO nano-composites. E-Polymers 1-10

37. Gesing A, Wolanski R (2001) Recycling light metals from end-oflife vehicle. JOM 53:21-23

38. Mourad A-HI, Bekheet N, El-Butch A et al (2005) The effects of process parameters on the mechanical properties of die drawn polypropylene. Polym Test 24:169-180

39. Mourad A-HI, Zaaroura N (2018) Impact of nanofillers incorporation on laminated nanocomposites performance. J Mater Eng Perform 27:4453-4461

40. Mourad A-HI, Mozumder MS, Mairpady A et al (2017) On the injection molding processing parameters of $\mathrm{HDPE}^{-\mathrm{TiO}_{2}}$ nanocomposites. Materials 10:85

41. Mohammad SM, Mourad AHI, Anusha M et al (2018) Effect of $\mathrm{TiO}_{2}$ Nanofiller concentration on the mechanical, thermal and biological properties of HDPE/TiO2 nanocomposites. J Mater Eng Perform 27:2166

42. Morel JC, Mesbah A, Oggero M et al (2001) Building houses with local materials: means to drastically reduce the environmental impact of construction. Build Environ 36:1119-1126

43. Khedari J, Suttisonk B, Pratinthong N et al (2001) New lightweight composite construction materials with low thermal conductivity. Cem Concr Compos 23:65-70

44. Ohama Y (2014) Polymers in concrete. CRC Press, London

Publisher's Note Springer Nature remains neutral with regard to jurisdictional claims in published maps and institutional affiliations. 